\title{
MicroRNAs in Podocyte Injury in Diabetic Nephropathy
}

\section{Hiroki Ishii', Shohei Kaneko ${ }^{1}$, Katsunori Yanai ${ }^{1}$, Akinori Aomatsu', Keiji Hirai', Susumu Ookawara' ${ }^{1}$ Kenichi Ishibashi ${ }^{2}$ and Yoshiyuki Morishita ${ }^{1 *}$}

' Division of Nephrology, First Department of Integrated Medicine, Saitama Medical Center, Jichi Medical University, Saitama, Japan, ${ }^{2}$ Department of Medical Physiology, Meiji Pharmaceutical University, Kiyose, Japan

Diabetic nephropathy is one of the major complications of diabetes mellitus and is the leading cause of end-stage renal disease worldwide. Podocyte injury contributes to the development of diabetic nephropathy. However, the molecules that regulate podocyte injury in diabetic nephropathy have not been fully clarified. MicroRNAs (miRNAs) are small non-coding RNAs that can inhibit the translation of target messenger RNAs. Previous reports have described alteration of the expression levels of many miRNAs in cultured podocyte cells stimulated with a high glucose concentration and podocytes in rodent models of diabetic nephropathy. The associations between podocyte injury and miRNA expression levels in blood, urine, and kidney in patients with diabetic nephropathy have also been reported. Moreover, modulation of the expression of several miRNAs has been shown to have protective effects against podocyte injury in diabetic nephropathy in cultured podocyte cells in vitro and in rodent models of diabetic nephropathy in vivo. Therefore, this review focuses on miRNAs in podocyte injury in diabetic nephropathy, with regard to their potential as biomarkers and miRNA modulation as a therapeutic option.

Keywords: podocyte injury, diabetic mellitus, microRNA, epigenetics, biomarker

\section{INTRODUCTION}

Diabetic nephropathy is one of the most severe microvascular complications, which affects over $40 \%$ of patients with diabetes mellitus (Fineberg et al., 2013). It is the leading cause of end-stage renal disease, which requires renal replacement therapy including dialysis and renal transplantation (Conserva et al., 2013). Diabetic nephropathy develops via multiple metabolic and hemodynamic

Abbreviations: APOL1, apolipoprotein L1; Bcl-2, B-cell lymphoma 2; BP, blood pressure; BUN, blood urea nitrogen; CD2AP, CD2-associated protein; CTGF, connective tissue growth factor; E2F3, E2F transcription factor 3; ErbB4, Erbb2 receptor tyrosine kinase 4; G3BP2, G3BP stress granule assembly factor 2; GBM, glomerular basement membrane; HDAC, histone deacetylase; HO-1, heme oxygenase-1; IL, interleukin; KD, knockdown; KRI, kidney artery resistance; MCP-1, monocyte chemotactic protein; MDA, malondialdehyde; Msk2, mitogen and stress-activated kinase; MTDH, metadherin; NADPH, nicotinamide adenine dinucleotide phosphate; NICD, notch intracellular domain; NOX, nicotinamide adenine dinucleotide phosphate oxidase; OE, overexpression; PPAR- $\gamma$, peroxisome proliferator-activated receptor- $\gamma$; PTEN, phosphatase and tensin homolog deleted on chromosome 10; Rock, rho-associated, coiled-coil-containing protein kinase 1; ROS, reactive oxygen species; SIRT7, sirtuin7; SMA, smooth muscle actin; SOD, superoxide dismutase; Spry1, sprouty homolog 1; STZ, streptozotocin; TGF, transforming growth factor; TIMP, tissue inhibitor of metalloproteases; TLR, toll-like receptor; TNF, tumor necrosis factor; TRIAP1, TP53-regulated inhibitor; TTP, tristetraprolin; TUNEL, TdT-mediated dUTP nick end labeling; UACR, urine albumin to creatinine ratio; UAER, urine albumin excretion rate; VEGF, vascular endothelial growth factor; WT-1, Wilm's tumor protein 1; wVF, Von Willebrand factor. 
pathways stimulated by persistent hyperglycemia. Various pathological changes such as abnormal mesangial expansion, glomerular hypertrophy, GBM thickening, and tubulointerstitial fibrosis are observed in diabetic nephropathy (Dronavalli et al., 2008). Additionally, podocyte injury has been shown to contribute to the development of diabetic nephropathy (Dalla Vestra et al., 2003; Susztak et al., 2006). Podocytes are highly differentiated glomerular epithelial cells attached to the outer surface of the GBM (Wolf et al., 2005). They play critical roles in maintaining the integrity of the glomerular filtration barrier (Wolf et al., 2005). Previous studies reported that, even at an early stage of diabetic nephropathy, the number of podocytes is drastically decreased, resulting in loss of the filtration barrier ability (Wolf et al., 2005; Fogo, 2011). Another study reported that podocyte injuries including the phenotypic change called podocyte mesenchymal transition, associated with disruption of podocyte architectural integrity and increased podocyte apoptosis, were observed in diabetic nephropathy (Shankland, 2006). However, the molecules that modulate these podocyte injuries in diabetic nephropathy have not been fully clarified.

MicroRNAs (miRNAs), which are single-stranded, short (1925 bases), non-coding RNAs, have been drawing attention as essential regulators of gene expression by repressing the translation of or degrading target messenger RNAs (mRNA) by RNA interference (Ambros, 2004; Cheng et al., 2020). Substantial evidence has revealed the roles of miRNAs in the development and progression of various diseases including diabetic nephropathy (Lorenzen et al., 2011). Furthermore, alterations of miRNA levels serve not only as diagnostic biomarkers, but also as therapeutic targets in various diseases, such as cancer and certain inflammatory diseases (Mouradian, 2012; Trionfini et al., 2015; Hosseinahli et al., 2018). Previous studies have also shown that miRNAs play pivotal roles in the development and progression of diabetic nephropathy, indicating that they may represent potential biomarkers and therapeutic options for diabetic nephropathy (Dewanjee and Bhattacharjee, 2018; Gholaminejad et al., 2018). This review focuses on miRNAs and their potential as biomarkers and therapeutic options in podocyte injury in diabetic nephropathy.

\section{THE PRODUCTION PROCESS OF MIRNA IN VIVO}

Single-stranded miRNA is initially transcribed from genomic DNA by RNA polymerase II in the nucleus (Lee et al., 2003). Then, this single-stranded RNA forms a hairpin structure called pri-miRNA by binding complementary sequences. Next, Drosha, an RNase III, cleaves the hairpin moiety of pri-miRNA. Subsequently, precursor miRNA (60-70 bases) is produced as an intermediate product (Denli et al., 2004). The produced precursor miRNA is mainly transported from the nucleus to the cytoplasm by exportin-5 (Okada et al., 2009). Then, the precursor miRNA is cleaved by the RNase III Dicer to shortform double-stranded RNA (21-24 bases) (Zhang et al., 2004). This double-stranded RNA is incorporated into the RNA-induced silencing complex (RISC) consisting of Ago proteins (Treiber et al., 2019). Then, double-stranded miRNA is dissolved into two single-stranded miRNAs (Treiber et al., 2019), after which the unstable single-stranded RNA is degraded. Finally, the residual stable single-stranded miRNA with RISC binds target messenger RNAs, resulting in inhibition of the translation of target mRNAs (Treiber et al., 2019).

Drosha or Dicer may cleave miRNA precursors at different points, as previously reported (Liang et al., 2017), after which miRNA variants called isomiRNAs are generated (Landgraf et al., 2007). IsomiRNAs are a few bases away from the $5^{\prime}$ or $3^{\prime}$ end of the reference sequences of miRNA, which have been registered in miRBase (Landgraf et al., 2007). The reference miRNA sequences are usually most highly expressed; however, certain isomiRNAs increase their expression level more than reference miRNAs under certain conditions. It has been suggested that at least some isomiRNAs may affect target selection, stability of miRNA, and loading ability (Guo and Chen, 2014).

\section{MECHANISM OF THE DEVELOPMENT OF PODOCYTE INJURY IN DIABETIC NEPHROPATHY}

Podocytes are highly specialized epithelial cells located on the surface of the GBM; they have a complicated cellular architecture with a cell body and numerous foot processes (Figure 1) (Perico et al., 2016). Adjacent foot processes of podocytes are connected by an intercellular junction called the slit diaphragm, which serves as a barrier to regulate the passage of macromolecules from the blood (Wartiovaara et al., 2004). A podocyte protein called nephrin, which is a transmembrane receptor molecule, is a central component in the formation and maintenance of the slit diaphragm (Welsh and Saleem, 2010; Martin and Jones, 2018).

Morphologically, injury of podocytes is characterized by their hypertrophy and detachment from the GBM, as well as foot process fusion and/or effacement with the dysregulation of nephrin (Figure 1) (Perico et al., 2016). Such injury is responsible for proteinuria, the accumulation of extracellular matrix components, and glomerulosclerosis (Shankland, 2006). Podocyte loss is considered to be an irreversible event associated with a decline in glomerular filtration function (Perico et al., 2016). Additionally, podocyte depletion and structural changes are important features in the pathogenesis of diabetic nephropathy (Pichaiwong et al., 2013) and are suggested to be predictors of the progression of this disease (Lee et al., 2015; Puelles and Bertram, 2015).

Podocyte injury has been reported to be induced by multiple signaling pathways in diabetic nephropathy (Kawanami et al., 2016). For example, a previous study reported that TGF$\beta_{1}$ and Smad7 directly induce podocyte apoptosis in diabetic nephropathy (Schiffer et al., 2001). Unlike Smad7, TGF- $\beta_{1}$ also induces podocyte apoptosis via the activation of p38 mitogenactivated protein (MAP) kinase and bcl-2-associated X protein (Bax), which activates the caspase-3 apoptotic pathway (Derynck and Zhang, 2003). TGF- $\beta_{1}$ increases mitochondrial membrane 
potential and oxygen consumption rate, inducing increases in the generation of ROS and podocyte apoptosis (Abe et al., 2013).

Mammalian target of rapamycin (mTOR) is also an important factor for high glucose-induced podocyte injury. For example, recent studies have shown that mTOR complex1 (mTORC1) activity is increased in podocytes in diabetic nephropathy (Godel et al., 2011; Inoki et al., 2011). High glucose causes podocyte apoptosis through the stimulation of oxidative stress and ROS generation with the activation of mTORC1 (Kitada et al., 2017). Indeed, an mTORC1 inhibitor, rapamycin, was shown to suppress podocyte injury caused by high glucose in diabetic nephropathy ( $\mathrm{Li}$ et al., 2019). In addition, genetic deletion of mTORC1 in mouse podocytes was found to induce proteinuria and progressive glomerulosclerosis (Godel et al., 2011). However, curtailing mTORC1 signaling in mice by genetically reducing the copy number of mTORC1 in podocytes was shown to ameliorate the progression of glomerular disease in diabetic nephropathy (Godel et al., 2011). These results suggested the need for tightly balanced mTOR activity in podocyte homeostasis in diabetic nephropathy (Godel et al., 2011; Li et al., 2019).

The Janus kinase/signal transducer and activator of transcription (JAK-STAT) signaling pathway has also been reported to play important roles in diabetic nephropathy (Marrero et al., 2006). In glomerular cells including podocytes, this pathway was shown to be activated in patients with even early-stage diabetic nephropathy (Berthier et al., 2009). OE of JAK2 in transgenic diabetic nephropathy model mice was shown to lead to a significant reduction in podocyte density (Zhang et al., 2017). In contrast, treatment with a JAK $1 / 2$ inhibitor, baricitinib, was shown to reduce albuminuria in patients with diabetic nephropathy (Zhang et al., 2017).

\section{CHANGES OF MIRNA EXPRESSION IN CULTURED PODOCYTE CELLS STIMULATED WITH A HIGH GLUCOSE CONCENTRATION, RODENT MODEL OF DIABETIC NEPHROPATHY, AND PATIENTS WITH DIABETIC NEPHROPATHY}

We searched for and reviewed miRNAs reported to be involved in podocyte injury in diabetic nephropathy, with regard to their potential as biomarkers and the possibility of modulating miRNAs as a therapeutic approach. Several studies have examined the changes of expression levels of miRNAs in cultured podocyte cells stimulated with a high glucose concentration in vitro, and in podocytes in rodent models with diabetic nephropathy in vivo (Table 1). The expression levels of 11 different miRNAs (miRNA-20b, -21, -27a, -29c, -134-5p, 193a, $-195,-217,-218,-503,-770-5 p)$ were shown to increase while the expression levels of 14 different miRNAs (miRNA-16-5p, $23 b,-25,-29 a,-30 s,-34 a,-34 c,-93,-130 a-3 p,-145-5 p,-146 a$, $-301 a-3 p,-423-5 p,-874)$ were shown to decrease in cultured podocytes in vitro or in podocytes in rodent models of diabetic

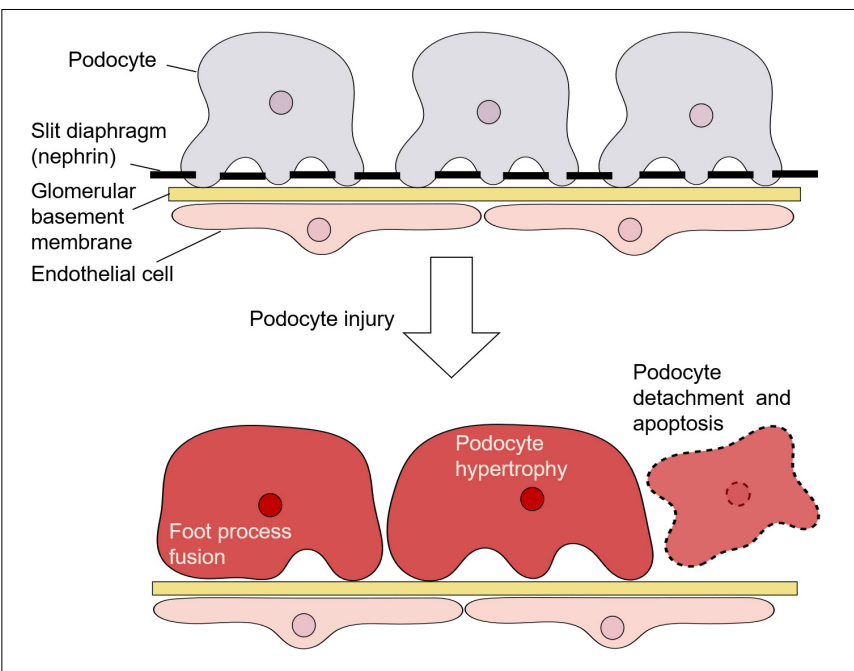

FIGURE 1 | Architecture of podocytes and podocyte injury.

nephropathy in vivo (Tables 1, 2) (Long et al., 2010, 2011; Chen et al., 2011, 2018; Lin et al., 2014; Liu et al., 2015, 2016, 2017; Badal et al., 2016; Yang et al., 2016; Zhang et al., 2016, 2019; Zhao et al., 2016; Guo et al., 2017; Kolling et al., 2017; Lee et al., 2017; Sun et al., 2017; Wang et al., 2017, 2018; Zhou et al., 2017; Jiang et al., 2018; Mishra et al., 2018; Qian et al., 2018; Xu et al., 2018; Yao et al., 2018; Duan et al., 2019; Zha et al., 2019; Wei et al., 2020). The associations between podocyte injury and miRNA expression levels in blood, urine, and kidney in patients with diabetic nephropathy were also reported (Table 2) (Long et al., 2011; Zhao et al., 2016; Guo et al., 2017; Kolling et al., 2017; Lee et al., 2017; Liu et al., 2017; Wang et al., 2017; Zhou et al., 2017; Xu et al., 2018; Ming et al., 2019). Furthermore, two different miRNAs (miRNA-21, -29c) in blood, one (miRNA-21) in urine and three (miRNA-21, -27a, -182-5p) in kidney tissues, were shown to increase, while two different miRNAs (miRNA-23b, -25) in blood, two (miRNA-23b, -29c) in urine, and three (miRNA-29c,-146a,-423-5p) in kidney tissues were shown to decrease in accordance with podocyte injuries in patients with diabetic nephropathy. These lines of evidence suggest that miRNAs are potential biomarkers of podocyte injury in diabetic nephropathy.

\section{METHODS OF MODULATION OF MIRNA EXPRESSION LEVELS ON PODOCYTE IN DIABETIC NEPHROPATHY}

Several vectors such as liposome nanoparticles and viral vectors with miRNAs, as well as chemical modifications of miRNAs, are employed to modulate miRNA expression levels on podocytes in diabetic nephropathy. miRNA-874 with adenoviral vectors was shown to ameliorate podocyte injury by overexpressing miRNA in diabetic nephropathy mouse models in vivo (Yao et al., 2018). In addition, chemically modified double-stranded miRNAs of miRNA-23b and miRNA-25 were shown to 
TABLE 1 | Associations between podocyte injury and miRNA expression levels in cultured podocyte cells and rodent models of diabetic nephropathy.

\begin{tabular}{|c|c|c|c|c|}
\hline miRNAs & Expression patterns & Sample & Predicted target mRNA & References \\
\hline miRNA-16-5p & $\downarrow$ & Cultured human podocyte & VEGFA & Duan et al., 2019 \\
\hline miRNA-20b & $\uparrow$ & Conditionally immortalized cultured mouse podocytes & SIRT7 & Wang et al., 2017 \\
\hline miRNA-21 & $\uparrow$ & $\begin{array}{l}\text { Conditionally immortalized cultured mouse podocytes. } \\
\text { Kidney (KK-Ay mice received high-fat diets). } \\
\text { Serum (KK-Ay mice received high-fat diets) }\end{array}$ & TIMP3Cdc25aCdk6 & $\begin{array}{l}\text { Kolling et al., 2017; } \\
\text { Chen et al., 2018; } \\
\text { Wang et al., } 2018\end{array}$ \\
\hline miRNA-23b & $\downarrow$ & $\begin{array}{l}\text { Cultured mouse podocytes. } \\
\text { Kidney (STZ-induced diabetic nephropathy mice, db/db). }\end{array}$ & G3BP2 & Zhao et al., 2016 \\
\hline miRNA-25 & $\downarrow$ & $\begin{array}{l}\text { Cultured mouse podocytes. } \\
\text { Kidney (STZ-induced diabetic nephropathy mice, db/db). } \\
\text { Serum (db/db). }\end{array}$ & Cdc42 & Liu et al., 2017 \\
\hline $\operatorname{miRNA}-27 a$ & $\uparrow$ & $\begin{array}{l}\text { Conditionally immortalized cultured murine podocyte. } \\
\text { Glomeruli (STZ-induced diabetic nephropathy rats). } \\
\text { Plasma (STZ-induced diabetic nephropathy rats). }\end{array}$ & PPAR- $\gamma$ & Zhou et al., 2017 \\
\hline miRNA-29a & $\downarrow$ & $\begin{array}{l}\text { Primary cultured mouse podocytes. } \\
\text { Immortalized cultured mouse podocyte. } \\
\text { Glomeruli (STZ-induced diabetic nephropathy mice). }\end{array}$ & HDAC & Lin et al., 2014 \\
\hline miRNA-29c & $\uparrow$ & $\begin{array}{l}\text { Conditionally immortalized cultured mouse podocytes. } \\
\text { Glomeruli (db/db). }\end{array}$ & TTPSpry1 & $\begin{array}{l}\text { Long et al., 2011; } \\
\text { Guo et al., } 2017\end{array}$ \\
\hline miRNA-30s & $\downarrow$ & $\begin{array}{l}\text { Conditionally immortalized cultured mouse podocytes. } \\
\text { Glomeruli (STZ-induced diabetic nephropathy rats). }\end{array}$ & $\mathrm{MTDH}$ & Liu et al., 2016 \\
\hline miRNA-34a & $\downarrow$ & Conditionally immortalized cultured mouse podocytes. & Notch-1 & Zhang et al., 2016 \\
\hline miRNA-34c & $\downarrow$ & Conditionally immortalized cultured mouse podocytes. & Notch1Jagged1 & Liu et al., 2015 \\
\hline miRNA-93 & $\downarrow$ & $\begin{array}{l}\text { Conditionally immortalized cultured mouse podocytes. } \\
\text { Glomeruli (db/db). }\end{array}$ & VEGF-AMsk2 & $\begin{array}{l}\text { Long et al., 2010; } \\
\text { Badal et al., } 2016\end{array}$ \\
\hline miRNA-130a-3p & $\downarrow$ & Conditionally immortalized cultured mouse podocytes. & $\mathrm{TNF}-\alpha$ & Jiang et al., 2018 \\
\hline miRNA-134-5p & $\uparrow$ & $\begin{array}{l}\text { Conditionally immortalized cultured human podocyte. } \\
\text { Kidney (db/db). }\end{array}$ & $\mathrm{Bcl}-2$ & Qian et al., 2018 \\
\hline miRNA-145-5p & $\downarrow$ & Cultured mouse podocytes. & Notch1 & Wei et al., 2020 \\
\hline miRNA-146a & $\downarrow$ & Glomeruli. & ErbB4Notch-1 & Lee et al., 2017 \\
\hline miRNA-193a & $\uparrow$ & Conditionally immortalized cultured human podocytes. & APOL1 & Mishra et al., 2018 \\
\hline miRNA-195 & $\uparrow$ & $\begin{array}{l}\text { Conditionally immortalized cultured mouse podocyte } \\
\text { Glomeruli (db/db). }\end{array}$ & $\mathrm{Bcl} 2$ & Chen et al., 2011 \\
\hline miRNA-217 & $\uparrow$ & Cultured mouse podocytes. & PTEN & Sun et al., 2017 \\
\hline $\operatorname{miRNA}-218$ & $\uparrow$ & Conditionally immortalized cultured mouse podocytes. & $\mathrm{HO}-1$ & Yang et al., 2016 \\
\hline miRNA-301a-3p & $\downarrow$ & Conditionally immortalized cultured mouse podocytes. & TNF- $\alpha$ & Jiang et al., 2018 \\
\hline miRNA-423-5p & $\downarrow$ & Conditionally immortalized cultured mouse podocytes. & Nox4 & Xu et al., 2018 \\
\hline miRNA-503 & $\uparrow$ & Cultured mouse podocytes. & E2F3 & Zha et al., 2019 \\
\hline miRNA-770-5p & $\uparrow$ & Cultured mouse podocyte. & TRIAP1 & Zhang et al., 2019 \\
\hline miRNA-874 & $\downarrow$ & $\begin{array}{l}\text { Conditionally immortalized cultured mouse podocytes. } \\
\text { Kidney (STZ-induced diabetic nephropathy rats). }\end{array}$ & TLR-4 & Yao et al., 2018 \\
\hline
\end{tabular}

inhibit podocyte injury in diabetic nephropathy mouse models in vivo (Zhao et al., 2016; Liu et al., 2017). However, there are still unresolved aspects of treatment of podocyte injury with miRNAs with/without vectors, such as efficient cellular uptake and intracellular re-release, as well as targeted delivery (Bartoszewski and Sikorski, 2019).

\section{THE EFFECTS OF EACH MIRNA EXPRESSION LEVELS ON PODOCYTE INJURY IN DIABETIC NEPHROPATHY}

Several previous studies reported that the OE or KD of different miRNAs had significant effects on podocyte injury in diabetic nephropathy in cultured podocyte cells stimulated with a high glucose concentration in vitro, and in rodent models with diabetic nephropathy in vivo (Tables 3A,B) (Long et al., 2010, 2011; Chen et al., 2011, 2018; Lin et al., 2014; Liu et al., 2015, 2016, 2017; Badal et al., 2016; Yang et al., 2016; Zhang et al., 2016, 2019; Zhao et al., 2016; Guo et al., 2017; Kolling et al., 2017; Lee et al., 2017; Sun et al., 2017; Wang et al., 2017, 2018; Zhou et al., 2017; Jiang et al., 2018; Mishra et al., 2018; Qian et al., 2018; Xu et al., 2018; Yao et al., 2018; Duan et al., 2019; Ming et al., 2019; Zha et al., 2019; Wei et al., 2020). These specific miRNAs are described below. The results of previous studies regarding modulating effects of miRNA on podocyte injury are summarized in Figure 2. miRNAs have been shown to be a novel class of key regulators in various biological processes in podocyte injury such as apoptosis, fibrosis, inflammation, migration, and proliferation (Figure 2). 
TABLE 2 | Associations between podocyte injury and miRNA expression levels in blood, urine, and kidney in patients with diabetic nephropathy.

\begin{tabular}{|c|c|c|c|c|}
\hline miRNA & $\begin{array}{c}\text { Expression } \\
\text { pattern }\end{array}$ & Sample & $\begin{array}{c}\text { Predicted } \\
\text { target } \\
\text { mRNA }\end{array}$ & References \\
\hline miRNA-21 & $\begin{array}{l}\uparrow \\
\uparrow \\
\uparrow\end{array}$ & $\begin{array}{c}\text { Plasma } \\
\text { Urine } \\
\text { Kidney }\end{array}$ & TIMP3 & $\begin{array}{c}\text { Kolling et al., } \\
2017\end{array}$ \\
\hline miRNA-23b & $\begin{array}{l}\downarrow \\
\downarrow\end{array}$ & $\begin{array}{l}\text { Serum } \\
\text { Urine }\end{array}$ & G3BP2 & $\begin{array}{c}\text { Zhao et al., } \\
2016\end{array}$ \\
\hline miRNA-25 & $\downarrow$ & Serum & $\begin{array}{l}\text { CDC } 42 \\
\text { Rap1a/b }\end{array}$ & $\begin{array}{l}\text { Liu et al., } \\
2017\end{array}$ \\
\hline miRNA-27a & $\uparrow$ & Kidney & $\begin{array}{l}\text { PPAR- } \gamma \text {, } \\
\text { activated } \beta \text { - } \\
\text { catenin } \\
\text { signaling }\end{array}$ & $\begin{array}{c}\text { Zhou et al., } \\
2017\end{array}$ \\
\hline miRNA-29c & $\begin{array}{l}\uparrow \\
\downarrow \\
\downarrow\end{array}$ & $\begin{array}{c}\text { Plasma } \\
\text { Urine } \\
\text { Renal } \\
\text { tissue }\end{array}$ & $\begin{array}{l}\text { ПТР } \\
\text { Spry1 }\end{array}$ & $\begin{array}{l}\text { Long et al., } \\
\text { 2011; Guo } \\
\text { et al., } 2017\end{array}$ \\
\hline miRNA-146a & $\downarrow$ & Kidney & $\begin{array}{l}\text { ErbB4 } \\
\text { Notch-1 }\end{array}$ & $\begin{array}{l}\text { Lee et al., } \\
2017\end{array}$ \\
\hline miRNA-182-5p & $\uparrow$ & $\begin{array}{c}\text { Kidney } \\
\text { (podocyte) }\end{array}$ & CD2AP & $\begin{array}{c}\text { Ming et al., } \\
2019\end{array}$ \\
\hline miRNA-423-5p & $\downarrow$ & kidney & Nox4 & $\begin{array}{c}\text { Xu et al., } \\
2018\end{array}$ \\
\hline
\end{tabular}

\section{miRNA-16-5p}

High glucose stimulation could inhibit miR-16-5p and promote VEGFA in human podocytes. The OE of miR-16-5p using human urine-derived stem cells (hUSCs) could improve the viability and apoptosis rate of podocytes after highglucose treatment in vitro. Furthermore, the OE of miRNA16-5p using hUSC exosomes containing overexpressed miR16-5p was shown to attenuate podocyte injury in diabetic nephropathy rats. It has been suggested that the protective effect of miRNA-16-5p against podocyte injury occurs through the inhibition of VEGF $A$, which has been reported to be an important mediator of diabetic nephropathy and is involved in the endogenous angiogenesis of endothelial cells (Duan et al., 2019).

\section{miRNA-20b}

The KD of miRNA-20b using a specific inhibitor of it carried by liposomal nanoparticles was shown to inhibit podocyte apoptosis by increasing the expression of sirtuin 7 , a target mRNA of miRNA-20b, in cultured mouse podocyte cells stimulated with a high glucose concentration (Wang et al., 2017).

\section{miRNA-21}

The OE of miRNA-21 using miRNA-21 mimic was shown to decrease the expression levels of nephrin and increase the expression levels of $\alpha$-SMA in cultured mouse podocyte cells with activation of the $\beta$-catenin pathway, and the TGF- $\beta_{1} /$ Smads pathway (Wang et al., 2018). Meanwhile, the KD of miRNA-21 expression dramatically reduced podocyte migration in cultured podocyte cells by regulating phosphatase and tensin homolog (Pten) (Kolling et al., 2017). Another study reported that the KD of miRNA-21 using a specific inhibitor of it decreased the expression levels of pro-inflammatory cytokines such as IL$1 \beta$ and TNF- $\alpha$, and alleviated kidney damage in STZ-induced diabetic nephropathy rats (Chen et al., 2018). These lines of evidence suggest that miRNA-21 promotes podocyte injury in diabetic nephropathy.

\section{miRNA-23b}

The OE of miRNA-23b in kidney by the weekly intravenous injection of miR-23b mimic was shown to have protective effects against diabetic nephropathy by improving podocyte injury, including flattening of the foot processes resulting in decreased microalbuminuria in a diabetic nephropathy mouse model (Zhao et al., 2016). In contrast, the inhibition of miRNA$23 \mathrm{~b}$ expression in kidney by intravenous injection with miR$23 \mathrm{~b}$ inhibitor was shown to increase kidney fibrosis, podocyte collapse, and proteinuria in wild-type mice (Zhao et al., 2016). The mechanism behind the protective effects of miRNA-23b in diabetic nephropathy has been suggested to occur via inhibition of the production of extracellular matrix proteins in diabetic nephropathy via the activation of p38 MAPK. In addition, Ras GTPase-activating protein $\mathrm{SH} 3$ domain-binding protein 2, which is considered a target mRNA of miRNA-23b, forms an miR-23b/G3BP2 feedback circuit involving p38 MAPK and p53 (Zhao et al., 2016). These lines of evidence suggest that miRNA-23b has protective effects against podocyte injury in diabetic nephropathy.

\section{miRNA-25}

The OE of miRNA-25 by intravenous injection of an miR-25 mimic via the tail vein was shown to alleviate podocyte injury in a diabetic mouse model in vivo (Liu et al., 2017). In contrast, KD of the expression of miRNA-25 by the intravenous injection of an miR-25 inhibitor via the tail vein was shown to cause podocyte injury in wild-type mice (Liu et al., 2017). The mechanism behind the protective effects of miRNA-25 in diabetic nephropathy has been suggested to occur via the inhibition of Ras-related genes including CDC 42, which is a downstream effector of Ras and Rapla/b primarily acting to modulate mitochondrion-derived oxidative stress (Liu et al., 2017). These lines of evidence suggest that miRNA- 25 would have protective effects in podocyte injury in diabetic nephropathy.

\section{miRNA-27a}

The KD of miRNA-27a was shown to ameliorate podocyte injury including apoptosis and decrease the levels of migration and invasion of cultured podocyte cells stimulated 
TABLE 3a | Effects of changes of miRNA expression levels on podocyte injury in diabetic nephropathy in vitro.

\begin{tabular}{|c|c|c|c|c|c|}
\hline miRNA & Model & Treatment & Biological effects & Target mRNA & References \\
\hline miRNA-16-5p & $\begin{array}{l}\text { Cultured human } \\
\text { podocyte }\end{array}$ & OE & $\begin{array}{c}\text { Caspase } 3 \downarrow, \text { Bax } \downarrow, \alpha-S M A \downarrow \text {, nephrin } \uparrow, \text { TNF- } \alpha \downarrow \\
\text { TGF- } \beta 1 \downarrow, \text { MCP- } 1 \downarrow,\end{array}$ & VEGFA & Duan et al., 2019 \\
\hline miRNA-20b & $\begin{array}{l}\text { Cultured mouse } \\
\text { podocyte }\end{array}$ & $\mathrm{KD}$ & Apoptosis $\downarrow$, Caspase $3 \downarrow$ & SIRT7 & Wang et al., 2017 \\
\hline miRNA-21 & $\begin{array}{l}\text { Cultured mouse } \\
\text { podocyte }\end{array}$ & OE & $\begin{array}{c}\text { Nephrin } \downarrow, \alpha \text {-SMA } \uparrow, \text { TGF- } \beta 1 \uparrow, \text { Smad3 } \uparrow, \text { Smad7 } \downarrow \text {, } \\
\beta \text {-catenin } \uparrow, \\
\text { Migration } \downarrow\end{array}$ & $\begin{array}{l}\text { Wnt/ } \beta \text {-catenin pathway } \\
\text { and the TGF- } \beta 1 / \text { Smads } \\
\text { pathway. } \\
\text { PTEN }\end{array}$ & $\begin{array}{l}\text { Kolling et al., 2017; } \\
\text { Wang et al., } 2018\end{array}$ \\
\hline miRNA-27a & $\begin{array}{l}\text { Cultured mouse } \\
\text { podocyte }\end{array}$ & $\mathrm{KD}$ & $\begin{array}{c}\beta \text {-catenin } \downarrow \text {, Snail } 1 \downarrow, \alpha \text {-SMA } \downarrow \text {, Podocine } \uparrow \text {, Migration } \downarrow \text {, } \\
\text { Invasion } \downarrow \text {, Apoptosis } \downarrow\end{array}$ & PPAR- $\gamma$ & Zhou et al., 2017 \\
\hline miRNA-29a & $\begin{array}{l}\text { Cultured mouse } \\
\text { podocyte }\end{array}$ & OE & $\begin{array}{l}\text { Ubiquitinated nephrin } \downarrow \text {, Nephrin } \uparrow \text {, Acetylated nephrin } \uparrow \text {, } \\
\qquad \text { WT- } 1 \uparrow \text { Apoptosis } \downarrow\end{array}$ & HDAC4 & Lin et al., 2014 \\
\hline miRNA-29c & $\begin{array}{l}\text { Cultured mouse } \\
\text { podocyte }\end{array}$ & $\mathrm{KD}$ & Apoptosis $\downarrow$, Caspase $3 \downarrow$, Fibronectin $\downarrow$, IL-6 6 , TNF- $\alpha \downarrow$ & $\begin{array}{l}\text { Spry1 } \\
\text { TTP }\end{array}$ & $\begin{array}{l}\text { Long et al., 2011; } \\
\text { Guo et al., } 2017\end{array}$ \\
\hline miRNA-30s & $\begin{array}{l}\text { Cultured mouse } \\
\text { podocyte }\end{array}$ & OE & $\begin{array}{l}\text { Apoptosis } \downarrow \text {, Mtdh } \downarrow \text {, } \\
\text { Bax } \downarrow \text {, Caspase } 3 \downarrow\end{array}$ & $\mathrm{MTDH}$ & Liu et al., 2016 \\
\hline miRNA-34a & $\begin{array}{l}\text { Cultured mouse } \\
\text { podocyte }\end{array}$ & $\mathrm{OE}$ & $\begin{array}{c}\text { Apoptosis } \downarrow \text {, Caspase } 3 \downarrow, \mathrm{Bcl}-2 \uparrow, \mathrm{Bax} \downarrow, \mathrm{p}-\mathrm{p} 53 \downarrow \text {, } \\
\beta \text {-Arrestin- } 1 \downarrow, \beta \text {-arrestin- } 2 \downarrow\end{array}$ & $\begin{array}{l}\text { Notch 1, Jagged } 1 \text {, } \\
\text { NICD, Hes 1, Hey } 1\end{array}$ & Zhang et al., 2016 \\
\hline miRNA-34c & $\begin{array}{l}\text { Cultured mouse } \\
\text { podocyte }\end{array}$ & $\mathrm{OE}$ & $\begin{array}{c}\text { Apoptosis } \downarrow \text {, Notch } 1 \downarrow \text {, } \\
\text { Hes } 1 \downarrow, \text { Hey } 1 \downarrow, \text { NICD } \downarrow, \text { Bcl- } 2 \uparrow, \text { Bax } \downarrow \text {, Cleaved } \\
\text { caspase- } 3 \downarrow, \text { p-p53 } \downarrow\end{array}$ & Notch1, Jaggged1 & Liu et al., 2015 \\
\hline miRNA-93 & $\begin{array}{l}\text { Cultured mouse } \\
\text { podocyte }\end{array}$ & $\mathrm{OE}$ & $\begin{array}{c}\text { CTGF } \downarrow \text {, Fibronectin } \downarrow \text {, Serpone } 1 \downarrow \text {, Rock } \downarrow, \text { WT- } 1 \downarrow, \alpha 3 \\
\text { collagen IV } \downarrow \text {, Fibronectin } \downarrow\end{array}$ & $\begin{array}{l}\text { Msk2 } \\
\text { VEGF-A }\end{array}$ & $\begin{array}{l}\text { Long et al., 2010; } \\
\text { Badal et al., } 2016\end{array}$ \\
\hline miRNA-130a-3p & $\begin{array}{l}\text { Cultured mouse } \\
\text { podocyte }\end{array}$ & OE & $\mathrm{TNF}-\alpha \downarrow, \mathrm{ROS} \downarrow, \mathrm{SOD} \uparrow, \mathrm{MDA} \downarrow$ & $\mathrm{TNF}-\alpha$ & Jiang et al., 2018 \\
\hline miRNA-134-5p & $\begin{array}{l}\text { Cultured human } \\
\text { podocyte }\end{array}$ & $\mathrm{KD}$ & Apoptosis $\downarrow$, Nephrin $\downarrow$, Cleaved caspase $3 \downarrow$ & $\mathrm{Bcl}-2$ & Qian et al., 2018 \\
\hline miRNA-145-5p & $\begin{array}{l}\text { Cultured mouse } \\
\text { podocyte }\end{array}$ & $\mathrm{OE}$ & Apoptosis $\downarrow$, Caspase $3 \downarrow$, Bcl- $2 \uparrow$, Bax $\downarrow$ & Notch1 & Wei et al., 2020 \\
\hline miRNA-182-5p & $\begin{array}{l}\text { Cultured mouse } \\
\text { podocyte }\end{array}$ & $\mathrm{KD}$ & Apoptosis $\downarrow$, Cell survival rate $\uparrow$ & CD2AP & Ming et al., 2019 \\
\hline miRNA-193a & $\begin{array}{l}\text { Cultured human } \\
\text { podocyte }\end{array}$ & $\mathrm{KD}$ & WT- $1 \uparrow$, PAX2 $\downarrow$ & APOL1 & Mishra et al., 2018 \\
\hline miRNA-195 & $\begin{array}{l}\text { Cultured mouse } \\
\text { podocyte }\end{array}$ & $\mathrm{KD}$ & $\begin{array}{c}\text { Bcl } 2 \uparrow, \text { Caspase } 3 \downarrow \text {, Caspase } 8 \downarrow, \text { WT- } 1 \uparrow, \\
\text { Synaptopodin } \uparrow, \text { Apoptosis } \downarrow\end{array}$ & $\mathrm{Bcl}-2$ & Chen et al., 2011 \\
\hline miRNA-217 & $\begin{array}{l}\text { Cultured mouse } \\
\text { podocyte }\end{array}$ & $\mathrm{KD}$ & $\begin{array}{c}\text { Nephrin } \uparrow \text {, Apoptosis } \downarrow \text {, Glucose uptake } \uparrow, \text { ROS } \\
\text { Production } \downarrow \text {, Synaptopodin } \uparrow \text {, Podocine } \uparrow, \text { LC3II/LC3I } \\
\uparrow \text {, Beclin- } 1 \uparrow, \text { p62 }\end{array}$ & PTEN & Sun et al., 2017 \\
\hline miRNA-218 & $\begin{array}{l}\text { Cultured mouse } \\
\text { podocyte }\end{array}$ & $\mathrm{OE}$ & Nephrin $\uparrow$, Apoptosis $\downarrow$, p-p38 $\downarrow$ & $\mathrm{HO}-1$ & Yang et al., 2016 \\
\hline miRNA-301a-3p & $\begin{array}{l}\text { Cultured mouse } \\
\text { podocyte }\end{array}$ & $\mathrm{OE}$ & TNF- $\alpha \downarrow$, ROS $\downarrow$, SOD $\uparrow$, MDA $\downarrow$ & TNF- $\alpha$ & Jiang et al., 2018 \\
\hline miRNA-423-5p & $\begin{array}{l}\text { Cultured mouse } \\
\text { podocyte }\end{array}$ & $\mathrm{OE}$ & $\begin{array}{c}\text { Proliferation } \uparrow, \text { Apoptosis } \downarrow \text {, NADPH oxidase activity } \uparrow \text {, } \\
\text { ROS production } \downarrow, I L-6 \downarrow, I L-1 \beta \downarrow \text {, TNF- } \alpha \downarrow \text {, MCP- } 1 \downarrow \\
\text { Cleaved caspase-3 } \downarrow \text {, Cleaved caspase- } 9 \downarrow \text {, Bax } \downarrow \text {, } \\
\text { Bcl- } 2 \uparrow, \text { Bax } \downarrow \text {, F-actin } \uparrow\end{array}$ & NOX4 & Xu et al., 2018 \\
\hline miRNA-503 & $\begin{array}{l}\text { Cultured mouse } \\
\text { podocyte }\end{array}$ & $\mathrm{KD}$ & $\begin{array}{c}\text { Migration } \downarrow \\
\text { Apoptosis } \downarrow\end{array}$ & E2F3 & Zha et al., 2019 \\
\hline miRNA-770-5p & $\begin{array}{l}\text { Cultured mouse } \\
\text { podocyte }\end{array}$ & $\mathrm{KD}$ & $\begin{array}{c}\text { Proliferation } \uparrow \\
\text { Apoptosis } \downarrow\end{array}$ & TRIAP1 & Zhang et al., 2019 \\
\hline miR-874 & $\begin{array}{l}\text { Cultured mouse } \\
\text { podocyte }\end{array}$ & $\mathrm{OE}$ & $\begin{array}{c}\text { Cell survival rate } \uparrow \text {, Proliferation } \uparrow, \text { Apoptosis } \downarrow, \mathrm{IL}-6 \downarrow \\
\qquad \mathrm{LL}-1 \beta \downarrow, \mathrm{TNF}-\alpha \downarrow\end{array}$ & TLR4 & Yao et al., 2018 \\
\hline
\end{tabular}

with a high glucose concentration in vitro (Zhou et al., 2017). Furthermore, KD of miRNA-27a expression via the intraperitoneal administration of miRNA-27a inhibitor was shown to mitigate podocyte injury, such as a decrease in their number, disruption of their architectural integrity, and effacement of foot processes, in a diabetic nephropathy rat model (Zhou et al., 2017). In contrast, the OE of miRNA27 a by the intraperitoneal administration of an miR-27a mimic was shown to exaggerate podocyte injury in a diabetic nephropathy rat model (Zhou et al., 2017). The 
TABLE 3b | Effects of changes of miRNA expression levels on podocyte injury in diabetic nephropathy in vivo.

\begin{tabular}{|c|c|c|c|c|c|c|}
\hline miRNA & Model & Treatment & $\begin{array}{l}\text { Method on miRNA } \\
\text { overexpression or } \\
\text { knockdown }\end{array}$ & Biological effects & Target mRNA & References \\
\hline miRNA-16-5p & $\begin{array}{l}\text { STZ-induced } \\
\text { diabetic } \\
\text { nephropathy rats }\end{array}$ & $\mathrm{OE}$ & $\begin{array}{l}\text { Human urine-derived } \\
\text { stem cells exosomes } \\
\text { containing } \\
\text { overexpressed } \\
\text { miR-16-5p were } \\
\text { injected via tail vein }\end{array}$ & $\begin{array}{l}\text { Podocyte number } \uparrow \text {, foot process width } \downarrow \text {, } \\
\text { podocyte fusion rate } \downarrow \text {, mesangial area } \downarrow \text {, } \\
\text { apoptosis } \downarrow \text {, TNF- } \alpha \downarrow \text {, TGF- } \beta \downarrow \text {, MCP- } 1 \downarrow\end{array}$ & $\begin{array}{l}\text { VEGFA. } \\
\text { Vascular } \\
\text { endothelial } \\
\text { growth factor } \mathrm{A} \text {. }\end{array}$ & Duan et al., 2019 \\
\hline miRNA-21 & $\begin{array}{l}\text { STZ-induced } \\
\text { diabetic } \\
\text { nephropathy rats. } \\
\text { STZ-induced } \\
\text { diabetic } \\
\text { nephropathy mice. }\end{array}$ & $\mathrm{KD}$ & $\begin{array}{l}\text { anti-miR-21 were } \\
\text { injected via tail vein. }\end{array}$ & $\begin{array}{c}\text { Serum: IL-1 } \downarrow \downarrow \text {, TNF- } \alpha \downarrow \text {, Blood: glucose } \downarrow \\
\text { Creatinine } \downarrow \text {, Blood urine nitrogen } \downarrow \text {, } \\
\text { Kidney: Bax } \downarrow \text {, Bcl- } 2 \uparrow \text {, Apoptosis } \downarrow \text {, } \\
\text { Mesangial expansion } \downarrow \text {, Mesangial expansion } \\
\downarrow \text {, Interstitial fibrosis } \downarrow \text {, Collagen la2 } \downarrow \text {, } \\
\text { Collagen III, CTGF, } \alpha \text {-SMA) } \downarrow \text {, Infiltrating } \\
\text { macrophages } \downarrow \text {, MCP- } 1 \downarrow \text { Albuminuria } \downarrow \text {, } \\
\text { Podocyte loss } \downarrow\end{array}$ & $\begin{array}{l}\text { TIMP3 } \\
\text { Cdc25a } \\
\text { Cdk6 }\end{array}$ & $\begin{array}{l}\text { Kolling et al., 2017; } \\
\text { Chen et al., } 2018\end{array}$ \\
\hline miRNA-23b & $\mathrm{db} / \mathrm{db}$ mice & $\mathrm{OE}$ & $\begin{array}{l}\text { miR-23b agomir were } \\
\text { injected via tail vein. }\end{array}$ & $\begin{array}{c}\text { Body weight } \downarrow \text {, Abdominal fat weight } \downarrow \text {, } \\
\text { Insulin resistance index } \downarrow \text { Insulin sensitivity } \uparrow \text {, } \\
\text { Kidney: Microalbuminuria } \downarrow \text {, } \\
\text { Albumin-to-creatinine ratio } \downarrow \text {, p53 } \downarrow \text {, } \\
\text { p38MAPK } \downarrow \text {, GBM thickening } \downarrow \text {, Podocyte } \\
\text { foot processes } \uparrow\end{array}$ & G3BP2 & Zhao et al., 2016 \\
\hline miRNA-25 & $\mathrm{db} / \mathrm{db}$ mice & $\mathrm{OE}$ & $\begin{array}{l}\text { miR-25 agomir were } \\
\text { injected via tail vein }\end{array}$ & $\begin{array}{c}\text { Proteinuria } \downarrow \\
\text { Kidney: Glomerular fibrosis } \downarrow \text {, } \alpha \text {-SMA } \downarrow \text {, Foot } \\
\text { process fusion of podocytes } \downarrow \text {, GBM } \\
\text { thickening } \downarrow \text {, BP } \downarrow \text {, KRI } \downarrow \text {, angiotensin } 1 \text { area } \\
\downarrow \text {, Renin area } \downarrow \text {, wVF } \downarrow \\
\text { serum: Renin } \downarrow \text {, Angiotensin } I \downarrow \text {, Angiotensin } \\
\| \downarrow \text {, Aldosterone } \downarrow\end{array}$ & CDC42 & Liu et al., 2017 \\
\hline miRNA-27a & $\begin{array}{l}\text { STZ-induced } \\
\text { diabetic } \\
\text { nephropathy rats }\end{array}$ & $\mathrm{KD}$ & $\begin{array}{l}\text { miR-27a inhibitor } \\
\text { were injected } \\
\text { intraperitoneally. }\end{array}$ & $\begin{array}{c}\text { Renal function } \uparrow \text {, Proteinuria } \downarrow \\
\text { Kidney: Podocyte number } \uparrow \text {, Effaced } \\
\text { podocyte foot processes } \downarrow \text {, PPAR- } \gamma \downarrow \text {, } \\
\beta \text {-catenin } \downarrow \text {, snail } 1 \downarrow, \alpha \text {-SMA } \downarrow \text {, } \\
\text { Synaptopodin } \uparrow, W T-1 \uparrow\end{array}$ & PPAR- $\gamma$ & Zhou et al., 2017 \\
\hline miRNA-29a & $\begin{array}{l}\text { STZ-induced } \\
\text { diabetic } \\
\text { nephropathy in } \\
\text { miRNA-29a } \\
\text { transgenic mice }\end{array}$ & $\mathrm{OE}$ & $\begin{array}{l}\text { miRNA-29a } \\
\text { transgenic mice }\end{array}$ & $\begin{array}{c}\text { Serum: Diabetes-induced hyperfiltration } \downarrow \text {, } \\
\text { Creatinine clearance } \uparrow \\
\text { Kidney: Kidney weight } \downarrow \text {, Urinary protein } \\
\text { levels } \downarrow \text {, Glomerular hypertrophy } \downarrow \text {, Desmin } \\
\downarrow \text {, Apotosis } \downarrow \text {, Nephrin } \uparrow, \text { WT- } 1 \uparrow, \text { TGF- } \beta 1 \downarrow \text {, } \\
\text { Fibronectin } \downarrow, \mid L-1 \beta \downarrow\end{array}$ & HDAC4 & Lin et al., 2014 \\
\hline miRNA-29c & $\mathrm{db} / \mathrm{db}$ mice & $\mathrm{KD}$ & $\begin{array}{l}\text { Chemically modified } \\
\text { antisense RNA } \\
\text { oligonucleotides were } \\
\text { injected } \\
\text { intraperitoneally. }\end{array}$ & $\begin{array}{c}\text { Kidney: Albuminuria } \downarrow \text {, Apoptosis } \downarrow \text {, } \\
\text { Mesangial matrix accumulation } \downarrow \text {, Fibronectin } \\
\downarrow\end{array}$ & Spry1 & Long et al., 2011 \\
\hline miRNA-93 & $\begin{array}{l}\text { miR-93 transgenic } \\
\text { db/db mice }\end{array}$ & $\mathrm{OE}$ & $\begin{array}{l}\text { miRNA-93 transgenic } \\
\text { mice }\end{array}$ & $\begin{array}{c}\text { Kidney: Albuminuria } \downarrow \text {, Mesangial matrix } \\
\text { expansion } \downarrow \text {, Desmin } \downarrow \text {, Podocyte loss } \downarrow \text {, } \\
\text { Synaptopodin } \uparrow \text {, Nephrin } \uparrow \text {, Foot process } \\
\text { effacement } \uparrow \text {, Slit diaphragm morphology } \uparrow \text {, } \\
\text { Glomerular basement membrane thickness } \\
\downarrow \text {, Foot process effacement } \downarrow \text {, Foot process } \\
\text { density } \uparrow\end{array}$ & Msk2 & Badal et al., 2016 \\
\hline miRNA-146a & $\begin{array}{c}\text { STZ-induced } \\
\text { diabetic } \\
\text { nephropathy in } \\
\text { miR-146a deficient } \\
\text { mice. }\end{array}$ & $\mathrm{KD}$ & $\begin{array}{l}\text { miR-146a-deficient } \\
\text { mice. }\end{array}$ & $\begin{array}{c}\text { Kidney: Mesangial sclerosis } \downarrow \text {, Foot process } \\
\text { effacement } \downarrow \text {, EGFR } \downarrow\end{array}$ & $\begin{array}{l}\text { ErbB4 } \\
\text { Notch-1 }\end{array}$ & Lee et al., 2017 \\
\hline miRNA-503 & $\begin{array}{l}\text { STZ-induced } \\
\text { diabetic } \\
\text { nephropathy rats. }\end{array}$ & $\mathrm{KD}$ & $\begin{array}{l}\text { miR-503 inhibitor was } \\
\text { injected intravenously. }\end{array}$ & $\begin{array}{c}\text { Proteinuria } \downarrow \text {, Serum creatinine } \downarrow \text {, Blood urea } \\
\text { nitrogen } \downarrow\end{array}$ & E2F3 & Zha et al., 2019 \\
\hline miR-874 & $\begin{array}{l}\text { STZ-induced } \\
\text { diabetic } \\
\text { nephropathy mice. }\end{array}$ & $\mathrm{OE}$ & $\begin{array}{l}\text { Adenovirus carrying } \\
\text { miR-874 were } \\
\text { injected intravenously }\end{array}$ & $\begin{array}{c}\text { Body weight } \uparrow \text {, Proteinuria } \downarrow \\
\text { Serum: Creatinine } \downarrow \text {, Blood urea nitrogen } \downarrow \\
\text { Kidney: IL- } 6 \downarrow \text {, IL-1 } 1 \beta \downarrow, \text { TNF- } \alpha \downarrow\end{array}$ & TLR4 & Yao et al., 2018 \\
\hline
\end{tabular}




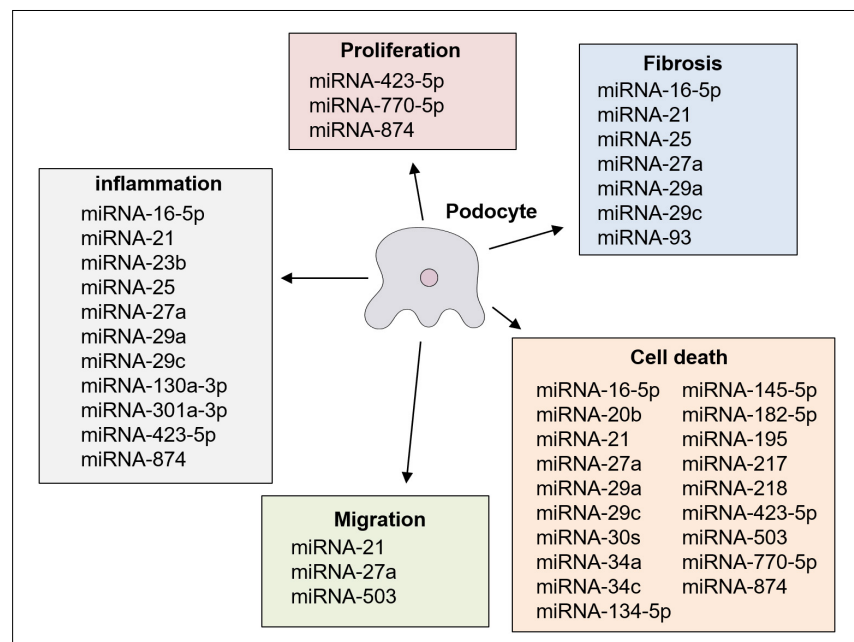

FIGURE 2 | Roles of miRNA in podocyte injury in diabetic nephropathy.

mechanism behind the protective effects of miRNA-27a against podocyte injury in diabetic nephropathy has been suggested to involve increases in proliferator-activated receptor$\gamma$ (PPAR- $\gamma$ ) and activated $\beta$-catenin (Zhou et al., 2017). PPAR- $\gamma$ phosphorylation induces $\beta$-catenin activation and triggers a series of $\beta$-catenin-dependent reprogramming events, including enhanced epithelial-mesenchymal transition, loss of podocyte-specific markers, and increased apoptosis (Zhou et al., 2017).

\section{miRNA-29a}

The KD of miRNA-29a using an antisense oligo of it was shown to promote the apoptosis and nephrin loss of podocytes in mice without diabetes mellitus (Lin et al., 2014). In contrast, the OE of miRNA-29a was shown to attenuate apoptosis in cultured podocyte cells stimulated with a high glucose concentration (Lin et al., 2014). The mechanism behind the protective effects of miRNA-29a against podocyte injury has been suggested to occur through the attenuation of histone deacetylase4-dependent nephrin deacetylation and ubiquitination, which accelerates podocyte apoptosis (Lin et al., 2014).

\section{miRNA-29c}

The KD of miRNA-29c using a specific inhibitor of it carried by a viral vector was shown to inhibit apoptosis and reduce inflammatory cytokines, mediated by OE of its target mRNAs [Spry1 and TTP] in cultured mouse podocyte cells (Long et al., 2011; Guo et al., 2017). Spry1 is known to inhibit the Ras/MEK/ERK pathway (Kim and Bar-Sagi, 2004). It has also been identified as a negative regulator of Rho $\mathrm{A}$ and its downstream effector Rho kinase, which plays a key role in diabetic nephropathy through non-canonical Wnt signaling (Miyoshi et al., 2004). In addition, TTP is a regulator of the stability of TNF- $\alpha$ mRNA (Deleault et al.,
2008). Furthermore, KD of miRNA-29c by a chemically modified antisense oligonucleotide was shown to reduce albuminuria and mesangial matrix accumulation in diabetic nephropathy mice in vivo (Long et al., 2011). These lines of evidence suggest that miRNA-29c would promote podocyte injury in diabetic nephropathy.

\section{miRNA-30s}

The OE of miRNA-30s using miRNA-30s mimic carried by liposomal nanoparticles was shown to attenuate the apoptosis of murine podocyte cells stimulated with a high glucose concentration in vitro (Liu et al., 2016). Inhibiting MTDH, a target of miRNA-30s that regulates apoptosis through the p38 MAPK pathway, which has an anti-apoptotic effect in TNF$\alpha$-induced apoptosis, was considered to be a mechanism behind the protective effects of miRNA-30c against injury to podocyte cells stimulated with a high glucose concentration in vitro (Liu et al., 2016).

\section{miRNA-34a}

The OE of miRNA-34a using an miRNA-34a mimic carried by liposomal nanoparticles was shown to inhibit apoptosis in cultured podocyte cells stimulated with a high glucose concentration in vitro by inhibiting the Notch signaling pathway (Zhang et al., 2016).

\section{miRNA-34c}

The OE of miRNA-34c by an miRNA-34c mimic carried by liposomal nanoparticles was shown to inhibit apoptosis in cultured podocyte cells stimulated with a high glucose concentration in vitro (Liu et al., 2015). Inhibiting the Notch signaling pathway by targeting Notch 1 and Jaggged 1 by miRNA$34 \mathrm{c}$ was assumed to be a mechanism behind the inhibition of apoptosis by miRNA-34a in podocyte cells stimulated with a high glucose concentration in vitro (Liu et al., 2015).

\section{miRNA-93}

The OE of miRNA-93 was shown to attenuate podocyte injury in diabetic nephropathy mice in vivo (Badal et al., 2016). The protective mechanism of miRNA-93 against podocyte injury has been suggested to occur through inhibition of the mitogenand stress-activated protein kinase 1 (Msk2), which is a kinase for Histone H3 Ser10 phosphorylation (H3S10P) and can lead to widespread changes in chromatin organization and gene transcription (Badal et al., 2016). Another study reported that the OE of miRNA-93 by an miRNA-93 mimic in cultured podocyte cells decreased the expression levels of collagen type IV alpha 3 and fibronectin, which are downstream targets of vascular epithelial growth factor, a target mRNA of miRNA-93, in vitro (Long et al., 2010). These lines of evidence suggest that miRNA-93 has protective effects against diabetic nephropathy. 


\section{miRNA-130a-3p/301a-3p}

The OE of miRNA-130a-3p/301a-3p using an miRNA-130a$3 \mathrm{p} / 301 \mathrm{a}-3 \mathrm{p}$ mimic carried by liposomal nanoparticles was shown to attenuate apoptosis by inhibiting TNF- $\alpha$ in cultured mouse podocyte cells stimulated with a high glucose concentration in vitro (Jiang et al., 2018).

\section{miRNA-134-5p}

The OE of miRNA-134-5p using an miRNA-134-5p mimic was shown to increase apoptosis in cultured human podocyte cells by inhibiting the expression of BCL-2, an apoptosis-related gene. The inhibition of miRNA-134-5p was also shown to have the opposite effect (Qian et al., 2018).

\section{miRNA-145-5p}

The OE of miRNA-145-5p using miRNA-145-5p mimic carried by liposomal nanoparticles inhibited high-glucose-induced apoptosis in vitro by suppressing the high-glucose-induced activation of Notch1, which is a vital factor in the Notch signaling pathway and plays an important role in podocyte apoptosis (Wei et al., 2020).

\section{miRNA-146a}

miRNA-146a-deficient mice were shown to exhibit more accelerated development of albuminuria, glomerular sclerosis, and podocyte injury including foot process effacement of podocyte cells upon the induction of diabetes mellitus by STZ administration (Lee et al., 2017). Erlotinib, an inhibitor of the epidermal growth factor family inhibitor, was shown to significantly decrease podocyte injury, including protection against foot process effacement, and suppress the reduction in podocyte numbers, in miRNA-146a-deficient animals upon the induction of diabetes mellitus by STZ administration (Lee et al., 2017).

\section{miRNA-182-5p}

The apoptosis of cells was suppressed by miRNA-182-5p inhibitor carried by liposomal nanoparticles and promoted by miR-182-5p mimics. In addition, the survival rate of cells was the highest after transfection with miR-182-5p inhibitor in vitro.

The protective effect of miRNA-182-5p on podocyte injury has been suggested to occur via a negative regulatory effect of miR182-5p on CD2AP, which is associated with the development of diabetic nephropathy (Ming et al., 2019).

\section{miRNA-193a}

The KD of miRNA-193a by an miRNA-193a inhibitor carried by liposomal nanoparticles was shown to maintain the phenotype of podocyte cells by inhibiting dedifferentiation in cultured podocyte cells stimulated with a high glucose concentration in vitro (Mishra et al., 2018). Silencing of APOL1, via the inhibition of miRNA-193a, is considered to be a mechanism of preserving the phenotype of podocyte cells (Mishra et al., 2018).

\section{miRNA-195}

The OE of miRNA-195 by an miRNA-195 mimic was shown to increase apoptosis via enhancing caspase cascades in cultured immortalized mouse podocyte cells in vitro (Chen et al., 2011). In contrast, miRNA-195 inhibitor was shown to provide significant protective effects against the apoptosis of podocyte cells (Chen et al., 2011).

\section{miRNA-217}

The KD of miRNA-217 expression by a specific inhibitor of it carried by liposomal nanoparticles was shown to attenuate decreased viability and cell apoptosis in cultured podocyte cells stimulated with a high glucose concentration in vitro (Sun et al., 2017). These protective effects of miRNA-217 were shown to occur through the autophagy pathway via targeting phosphatase and tensin homolog deleted from chromosome 10, which can negatively regulate $\mathrm{PI} 3 \mathrm{~K} / \mathrm{AKT} / \mathrm{mTOR}$ signaling, subsequently enhancing autophagy and being a target mRNA of miRNA-217 (Sun et al., 2017).

\section{miRNA-218}

The OE of miRNA-218 using a miRNA-218 mimic carried by liposomal nanoparticles was shown to increase apoptosis in cultured immortalized mouse podocyte cells stimulated with a high glucose concentration. The inhibition of miRNA-218 was also shown to have the opposite effects in vitro (Yang et al., 2016). These effects of miRNA-218 on podocyte cells were shown to be caused by the inhibition of heme oxygenase (HO), which is involved in antioxidant defense and is a key cytoprotective enzyme, and the activation of $\mathrm{p} 38$-mitogen-activated protein kinase (MAPK), a pro-apoptotic molecule and target mRNA of miRNA-218 (Yang et al., 2016).

\section{miRNA-423-5p}

The OE of miRNA-423-5p using an miRNA-423-5p mimic carried by liposomal nanoparticles was shown to inhibit apoptosis by reducing reactive ROS production, migratory activity, and cytoskeletal damage in cultured immortalized mouse podocyte cells stimulated with a high glucose concentration in vitro (Xu et al., 2018). These protective effects of miRNA423-5p against podocyte injury were shown to be caused by the inhibition of NADPH reduced oxidase 4 (Nox4), which is a target mRNA of miRNA-423-5p (Xu et al., 2018). Nox4 is characterized by the constitutive release of hydrogen peroxide, which has been 
identified as the major enzymatic source of ROSs in diverse renal cells (Sedeek et al., 2013).

\section{miRNA-503}

The podocyte apoptosis stimulated with a high glucose concentration was strongly repressed by the downregulation of miRNA-503 carried by liposomal nanoparticles in vitro. Furthermore, intravenous injection of miR-503 inhibitor into diabetic rats resulted in decreases of proteinuria, serum creatinine, and BUN levels. These effects of miRNA-503 were shown to be caused by the inhibition of E2F3, which modulates various cellular processes, such as apoptosis, differentiation, and development, with E2F1, 2, and 3 as the transcriptional activators (Zha et al., 2019).

\section{miRNA-770-5p}

High-glucose-induced cell apoptosis and decreased cell proliferation ability were significantly inhibited by miR-770-5p inhibitor using liposomal nanoparticles in vitro. The suppression of TRIAP1 by miR-770 exerts this protective effect on podocytes (Zhang et al., 2019).

\section{miRNA-874}

The OE of miRNA-874 was shown to increase the survival and proliferative ability of cultured mouse podocyte cells stimulated with a high glucose concentration by inhibiting the expression level of toll-like receptor 4 (TLR4), a target mRNA of miRNA-874 in vitro (Yao et al., 2018). TLR4 is reported to be upregulated in diabetic patients, and it can increase the expression of interleukin-6 (IL-6), tumor necrosis factor- $\alpha$ (TNF$\alpha$ ), and IL-1 $\beta$. Additionally, the OE of miRNA-874 in kidney by injecting adenovirus carrying an miR-874 mimic was shown to significantly decrease the infiltration of inflammatory cells and the expression levels of inflammatory cytokines such as IL-6,

\section{REFERENCES}

Abe, Y., Sakairi, T., Beeson, C., and Kopp, J. B. (2013). TGF-betal stimulates mitochondrial oxidative phosphorylation and generation of reactive oxygen species in cultured mouse podocytes, mediated in part by the mTOR pathway. Am. J. Physiol. Renal Physiol. 305, F1477-F1490. doi: 10.1152/ajprenal.00182. 2013

Ambros, V. (2004). The functions of animal microRNAs. Nature 431, 350-355. doi: $10.1038 /$ nature02871

Badal, S. S., Wang, Y., Long, J., Corcoran, D. L., Chang, B. H., Truong, L. D., et al. (2016). miR-93 regulates Msk2-mediated chromatin remodelling in diabetic nephropathy. Nat. Commun. 7:12076. doi: 10.1038/ncomms12076

Bartoszewski, R., and Sikorski, A. F. (2019). Editorial focus: understanding offtarget effects as the key to successful RNAi therapy. Cell Mol. Biol. Lett. 24:69. doi: 10.1186/s11658-019-0196-3

Berthier, C. C., Zhang, H., Schin, M., Henger, A., Nelson, R. G., Yee, B., et al. (2009). Enhanced expression of Janus kinase-signal transducer and activator of transcription pathway members in human diabetic nephropathy. Diabetes Metab. Res. Rev. 58, 469-477. doi: 10.2337/db08-1328
IL-1 $\beta$, and TNF- $\alpha$ with inhibition of the expression of TLR4 in kidney, resulting in decreased albuminuria and increased renal function in a rat diabetic nephropathy model in vivo (Yao et al., 2018).

\section{DISCUSSION}

This review focuses on miRNAs in podocyte injury in diabetic nephropathy, with regard to their potential as biomarkers and miRNA modulation as a therapeutic option. miRNAs have been shown to play pivotal roles in the development of podocyte injury in diabetic nephropathy, indicating that they may represent potential biomarkers and therapeutic options. Further clinical studies are needed to investigate their usefulness in detail.

\section{AUTHOR CONTRIBUTIONS}

HI drafted the manuscript. SK, KY, and AA participated in the discussion and revision of this manuscript. $\mathrm{KH}, \mathrm{SO}$, and $\mathrm{KI}$ contributed critical analysis. YM conceived the whole program, and extensively revised the manuscript. All authors contributed to the article and approved the submitted version.

\section{FUNDING}

This research was supported by AMED under Grant Number 19ek0210094h0003 and JSPS KAKENHI under Grant Number JP17K09708.

\section{ACKNOWLEDGMENTS}

We would like to thank Toshihiro Takizawa and Kyi-ThaThu Chaw for useful discussions. We thank Edanz (www. edanzediting.co.jp) for editing the English text of a draft of this manuscript.

Chen, X., Zhao, L., Xing, Y., and Lin, B. (2018). Down-regulation of microRNA21 reduces inflammation and podocyte apoptosis in diabetic nephropathy by relieving the repression of TIMP3 expression. Biomed. Pharmacother. 108, 7-14. doi: 10.1016/j.biopha.2018.09.007

Chen, Y. Q., Wang, X. X., Yao, X. M., Zhang, D. L., Yang, X. F., Tian, S. F., et al. (2011). MicroRNA-195 promotes apoptosis in mouse podocytes via enhanced caspase activity driven by BCL2 insufficiency. Am. J. Nephrol. 34, 549-559. doi: 10.1159/000333809

Cheng, Y., Wang, D., Wang, F., Liu, J., Huang, B., Baker, M. A., et al. (2020). Endogenous miR-204 protects the kidney against chronic injury in hypertension and diabetes. J. Am. Soc. Nephrol. 31, 1539-1554. doi: 10.1681/ asn. 2019101100

Conserva, F., Pontrelli, P., Accetturo, M., and Gesualdo, L. (2013). The pathogenesis of diabetic nephropathy: focus on microRNAs and proteomics. J. Nephrol. 26, 811-820. doi: 10.5301/jn.5000262

Dalla Vestra, M., Masiero, A., Roiter, A. M., Saller, A., Crepaldi, G., and Fioretto, P. (2003). Is podocyte injury relevant in diabetic nephropathy? Studies in patients with type 2 diabetes. Diabetes Metab. Res. Rev. 52, 1031-1035. doi: 10.2337/ diabetes.52.4.1031 
Deleault, K. M., Skinner, S. J., and Brooks, S. A. (2008). Tristetraprolin regulates TNF TNF-alpha mRNA stability via a proteasome dependent mechanism involving the combined action of the ERK and p38 pathways. Mol. Immunol. 45, 13-24. doi: 10.1016/j.molimm.2007.05.017

Denli, A. M., Tops, B. B., Plasterk, R. H., Ketting, R. F., and Hannon, G. J. (2004). Processing of primary microRNAs by the Microprocessor complex. Nature 432, 231-235. doi: 10.1038/nature03049

Derynck, R., and Zhang, Y. E. (2003). Smad-dependent and Smad-independent pathways in TGF-beta family signalling. Nature 425, 577-584. doi: 10.1038/ nature 02006

Dewanjee, S., and Bhattacharjee, N. (2018). MicroRNA: a new generation therapeutic target in diabetic nephropathy. Biochem. Pharmacol. 155, 32-47. doi: 10.1016/j.bcp.2018.06.017

Dronavalli, S., Duka, I., and Bakris, G. L. (2008). The pathogenesis of diabetic nephropathy. Nat. Clin. Pract. Endocrinol. Metab. 4, 444-452. doi: 10.1038/ ncpendmet0894

Duan, Y. R., Chen, B. P., Chen, F., Yang, S. X., Zhu, C. Y., Ma, Y. L., et al. (2019). Exosomal microRNA-16-5p from human urine-derived stem cells ameliorates diabetic nephropathy through protection of podocyte. J. Cell. Mol. Med. [Epub ahead of print]. doi: $10.1111 /$ jcmm. 14558

Fineberg, D., Jandeleit-Dahm, K. A., and Cooper, M. E. (2013). Diabetic nephropathy: diagnosis and treatment. Nat. Rev. Endocrinol. 9, 713-723. doi: $10.1038 /$ nrendo.2013.184

Fogo, A. B. (2011). The targeted podocyte. J. Clin. Invest. 121, 2142-2145. doi: $10.1172 /$ jci57935

Gholaminejad, A., Abdul Tehrani, H., and Gholami Fesharaki, M. (2018). Identification of candidate microRNA biomarkers in diabetic nephropathy: a meta-analysis of profiling studies. J. Nephrol. 31, 813-831. doi: 10.1007/s40620018-0511-5

Godel, M., Hartleben, B., Herbach, N., Liu, S., Zschiedrich, S., Lu, S., et al. (2011). Role of mTOR in podocyte function and diabetic nephropathy in humans and mice. J. Clin. Invest. 121, 2197-2209. doi: 10.1172/jci44774

Guo, J., Li, J., Zhao, J., Yang, S., Wang, L., Cheng, G., et al. (2017). MiRNA-29c regulates the expression of inflammatory cytokines in diabetic nephropathy by targeting tristetraprolin. Sci. Rep. 7:2314. doi: 10.1038/s41598-017-01027-5

Guo, L., and Chen, F. (2014). A challenge for miRNA: multiple isomiRs in miRNAomics. Gene 544, 1-7. doi: 10.1016/j.gene.2014.04.039

Hosseinahli, N., Aghapour, M., Duijf, P. H. G., and Baradaran, B. (2018). Treating cancer with microRNA replacement therapy: a literature review. J. Cell. Physiol. 233, 5574-5588. doi: 10.1002/jcp.26514

Inoki, K., Mori, H., Wang, J., Suzuki, T., Hong, S., Yoshida, S., et al. (2011). mTORC1 activation in podocytes is a critical step in the development of diabetic nephropathy in mice. J. Clin. Invest. 121, 2181-2196. doi: 10.1172/jci44771

Jiang, Y., Wang, W., Liu, Z. Y., Xie, Y., Qian, Y., and Cai, X. N. (2018). Overexpression of miR-130a-3p/301a-3p attenuates high glucose-induced MPC5 podocyte dysfunction through suppression of TNF-alpha signaling. Exp. Ther. Med. 15, 1021-1028. doi: 10.3892/etm.2017.5465

Kawanami, D., Matoba, K., and Utsunomiya, K. (2016). Signaling pathways in diabetic nephropathy. Histol. Histopathol. 31, 1059-1067. doi: 10.14670/hh11-777

Kim, H. J., and Bar-Sagi, D. (2004). Modulation of signalling by Sprouty: a developing story. Nat. Rev. Mol. Cell Biol. 5, 441-450. doi: 10.1038/nrm1400

Kitada, M., Ogura, Y., Monno, I., and Koya, D. (2017). Regulating autophagy as a therapeutic target for diabetic nephropathy. Curr. Diab. Rep. 17:53. doi: 10.1007/s11892-017-0879-y

Kolling, M., Kaucsar, T., Schauerte, C., Hubner, A., Dettling, A., Park, J. K., et al. (2017). Therapeutic miR-21 silencing ameliorates diabetic kidney disease in mice. Mol. Ther. 25, 165-180. doi: 10.1016/j.ymthe.2016.08.001

Landgraf, P., Rusu, M., Sheridan, R., Sewer, A., Iovino, N., Aravin, A., et al. (2007). A mammalian microRNA expression atlas based on small RNA library sequencing. Cell 129, 1401-1414. doi: 10.1016/j.cell.2007.04.040

Lee, H. W., Khan, S. Q., Khaliqdina, S., Altintas, M. M., Grahammer, F., Zhao, J. L., et al. (2017). Absence of miR-146a in podocytes increases risk of diabetic glomerulopathy via up-regulation of ErbB4 and notch-1. J. Biol. Chem. 292, 732-747. doi: 10.1074/jbc.M116.753822

Lee, S. H., Moon, S. J., Paeng, J., Kang, H. Y., Nam, B. Y., Kim, S., et al. (2015). Podocyte hypertrophy precedes apoptosis under experimental diabetic conditions. Apoptosis 20, 1056-1071. doi: 10.1007/s10495-015-1134-0
Lee, Y., Ahn, C., Han, J., Choi, H., Kim, J., Yim, J., et al. (2003). The nuclear RNase III Drosha initiates microRNA processing. Nature 425, 415-419. doi: 10.1038 /nature01957

Li, Q., Zeng, Y., Jiang, Q., Wu, C., and Zhou, J. (2019). Role of mTOR signaling in the regulation of high glucose-induced podocyte injury. Exp. Ther. Med. 17, 2495-2502. doi: 10.3892/etm.2019.7236

Liang, T., Yu, J., Liu, C., and Guo, L. (2017). IsomiR expression patterns in canonical and Dicer-independent microRNAs. Mol. Med. Rep. 15, 1071-1078. doi: 10.3892/mmr.2017.6117

Lin, C. L., Lee, P. H., Hsu, Y. C., Lei, C. C., Ko, J. Y., Chuang, P. C., et al. (2014). MicroRNA-29a promotion of nephrin acetylation ameliorates hyperglycemiainduced podocyte dysfunction. J. Am. Soc. Nephrol. 25, 1698-1709. doi: 10. 1681/asn.2013050527

Liu, W. T., Peng, F. F., Li, H. Y., Chen, X. W., Gong, W. Q., Chen, W. J., et al. (2016). Metadherin facilitates podocyte apoptosis in diabetic nephropathy. Cell Death Dis. 7:e2477. doi: 10.1038/cddis.2016.335

Liu, X. D., Zhang, L. Y., Zhu, T. C., Zhang, R. F., Wang, S. L., and Bao, Y. (2015). Overexpression of miR-34c inhibits high glucose-induced apoptosis in podocytes by targeting Notch signaling pathways. Int. J. Clin. Exp. Pathol. 8, 4525-4534.

Liu, Y., Li, H., Liu, J., Han, P., Li, X., Bai, H., et al. (2017). Variations in MicroRNA25 expression influence the severity of diabetic kidney disease. J. Am. Soc. Nephrol. 28, 3627-3638. doi: 10.1681/asn.2015091017

Long, J., Wang, Y., Wang, W., Chang, B. H., and Danesh, F. R. (2010). Identification of microRNA-93 as a novel regulator of vascular endothelial growth factor in hyperglycemic conditions. J. Biol. Chem. 285, 23457-23465. doi: 10.1074/jbc. M110.136168

Long, J., Wang, Y., Wang, W., Chang, B. H., and Danesh, F. R. (2011). MicroRNA$29 \mathrm{c}$ is a signature microRNA under high glucose conditions that targets Sprouty homolog 1, and its in vivo knockdown prevents progression of diabetic nephropathy. J. Biol. Chem. 286, 11837-11848. doi: 10.1074/jbc.M110. 194969

Lorenzen, J. M., Haller, H., and Thum, T. (2011). MicroRNAs as mediators and therapeutic targets in chronic kidney disease. Nat. Rev. Nephrol. 7, 286-294. doi: 10.1038/nrneph.2011.26

Marrero, M. B., Banes-Berceli, A. K., Stern, D. M., and Eaton, D. C. (2006). Role of the JAK/STAT signaling pathway in diabetic nephropathy. Am. J. Physiol. Renal Physiol. 290, F762-F768. doi: 10.1152/ajprenal.00181.2005

Martin, C. E., and Jones, N. (2018). Nephrin signaling in the podocyte: an updated view of signal regulation at the slit diaphragm and beyond. Front Endocrinol. 9:302. doi: 10.3389/fendo.2018.00302

Ming, L., Ning, J., Ge, Y., Zhang, Y., and Ruan, Z. (2019). Excessive apoptosis of podocytes caused by dysregulation of microRNA-182-5p and CD2AP confers to an increased risk of diabetic nephropathy. J. Cell. Biochem. 120, 16516-16523. doi: $10.1002 /$ jcb.28911

Mishra, A., Ayasolla, K., Kumar, V., Lan, X., Vashistha, H., Aslam, R., et al. (2018). Modulation of apolipoprotein L1-microRNA-193a axis prevents podocyte dedifferentiation in high-glucose milieu. Am. J. Physiol. Renal Physiol. 314, F832-F843. doi: 10.1152/ajprenal.00541.2017

Miyoshi, K., Wakioka, T., Nishinakamura, H., Kamio, M., Yang, L., Inoue, M., et al. (2004). The Sprouty-related protein, Spred, inhibits cell motility, metastasis, and Rho-mediated actin reorganization. Oncogene 23, 5567-5576. doi: 10.1038/ sj.onc.1207759

Mouradian, M. M. (2012). MicroRNAs in Parkinson's disease. Neurobiol. Dis. 46, 279-284. doi: 10.1016/j.nbd.2011.12.046

Okada, C., Yamashita, E., Lee, S. J., Shibata, S., Katahira, J., Nakagawa, A., et al. (2009). A high-resolution structure of the pre-microRNA nuclear export machinery. Science 326, 1275-1279. doi: 10.1126/science.1178705

Perico, L., Conti, S., Benigni, A., and Remuzzi, G. (2016). Podocyte-actin dynamics in health and disease. Nat. Rev. Nephrol. 12, 692-710. doi: 10.1038/nrneph. 2016.127

Pichaiwong, W., Hudkins, K. L., Wietecha, T., Nguyen, T. Q., Tachaudomdach, C., Li, W., et al. (2013). Reversibility of structural and functional damage in a model of advanced diabetic nephropathy. J. Am. Soc. Nephrol. 24, 1088-1102. doi: 10.1681/asn.2012050445

Puelles, V. G., and Bertram, J. F. (2015). Counting glomeruli and podocytes: rationale and methodologies. Curr. Opin. Nephrol. Hypertens. 24, 224-230. doi: $10.1097 / \mathrm{mnh} .0000000000000121$ 
Qian, X., Tan, J., Liu, L., Chen, S., You, N., Yong, H., et al. (2018). MicroRNA-134$5 \mathrm{p}$ promotes high glucose-induced podocyte apoptosis by targeting bcl-2. Am. J. Transl. Res. 10, 989-997.

Schiffer, M., Bitzer, M., Roberts, I. S., Kopp, J. B., ten Dijke, P., Mundel, P., et al. (2001). Apoptosis in podocytes induced by TGF-beta and Smad7. J. Clin. Invest. 108, 807-816. doi: 10.1172/jci12367

Sedeek, M., Nasrallah, R., Touyz, R. M., and Hebert, R. L. (2013). NADPH oxidases, reactive oxygen species, and the kidney: friend and foe. J. Am. Soc. Nephrol. 24, 1512-1518. doi: 10.1681/asn.2012111112

Shankland, S. J. (2006). The podocyte's response to injury: role in proteinuria and glomerulosclerosis. Kidney Int. 69, 2131-2147. doi: 10.1038/sj.ki.5000410

Sun, J., Li, Z. P., Zhang, R. Q., and Zhang, H. M. (2017). Repression of miR-217 protects against high glucose-induced podocyte injury and insulin resistance by restoring PTEN-mediated autophagy pathway. Biochem. Biophys. Res. Commun. 483, 318-324. doi: 10.1016/j.bbrc.2016.12.145

Susztak, K., Raff, A. C., Schiffer, M., and Bottinger, E. P. (2006). Glucose-induced reactive oxygen species cause apoptosis of podocytes and podocyte depletion at the onset of diabetic nephropathy. Diabetes Metab. Res. Rev 55, 225-233. doi: 10.2337/diabetes.55.01.06.db05-0894

Treiber, T., Treiber, N., and Meister, G. (2019). Regulation of microRNA biogenesis and its crosstalk with other cellular pathways. Nat. Rev. Mol. Cell Biol. 20, 5-20. doi: 10.1038/s41580-018-0059-1

Trionfini, P., Benigni, A., and Remuzzi, G. (2015). MicroRNAs in kidney physiology and disease. Nat. Rev. Nephrol. 11, 23-33. doi: 10.1038/nrneph. 2014.202

Wang, X., Gao, Y., Tian, N., Zou, D., Shi, Y., and Zhang, N. (2018). Astragaloside IV improves renal function and fibrosis via inhibition of miR-21-induced podocyte dedifferentiation and mesangial cell activation in diabetic mice. Drug Des. Devel. Ther. 12, 2431-2442. doi: 10.2147/dddt.S170840

Wang, X., Lin, B., Nie, L., and Li, P. (2017). microRNA-20b contributes to high glucose-induced podocyte apoptosis by targeting SIRT7. Mol. Med. Rep. 16, 5667-5674. doi: 10.3892/mmr.2017.7224

Wartiovaara, J., Ofverstedt, L. G., Khoshnoodi, J., Zhang, J., Makela, E., Sandin, S., et al. (2004). Nephrin strands contribute to a porous slit diaphragm scaffold as revealed by electron tomography. J. Clin. Invest. 114, 1475-1483. doi: 10.1172/ jci22562

Wei, B., Liu, Y. S., and Guan, H. X. (2020). MicroRNA-145-5p attenuates high glucose-induced apoptosis by targeting the Notch signaling pathway in podocytes. Exp. Ther. Med. 19, 1915-1924. doi: 10.3892/etm.2020.8427

Welsh, G. I., and Saleem, M. A. (2010). Nephrin-signature molecule of the glomerular podocyte? J. Pathol. 220, 328-337. doi: 10.1002/path.2661

Wolf, G., Chen, S., and Ziyadeh, F. N. (2005). From the periphery of the glomerular capillary wall toward the center of disease: podocyte injury comes of age in diabetic nephropathy. Diabetes Metab. Res. Rev. 54, 1626-1634. doi: 10.2337/ diabetes.54.6.1626
Xu, Y., Zhang, J., Fan, L., and He, X. (2018). miR-423-5p suppresses high-glucoseinduced podocyte injury by targeting Nox4. Biochem. Biophys. Res. Commun. 505, 339-345. doi: 10.1016/j.bbrc.2018.09.067

Yang, H., Wang, Q., and Li, S. (2016). MicroRNA-218 promotes high glucoseinduced apoptosis in podocytes by targeting heme oxygenase-1. Biochem. Biophys. Res. Commun. 471, 582-588. doi: 10.1016/j.bbrc.2016.02.028

Yao, T., Zha, D., Gao, P., Shui, H., and Wu, X. (2018). MiR-874 alleviates renal injury and inflammatory response in diabetic nephropathy through targeting toll-like receptor-4. J. Cell. Physiol. 234, 871-879. doi: 10.1002/jcp.26908

Zha, F., Bai, L., Tang, B., Li, J., Wang, Y., Zheng, P., et al. (2019). MicroRNA503 contributes to podocyte injury via targeting E2F3 in diabetic nephropathy. J. Cell. Biochem. 120, 12574-12581. doi: 10.1002/jcb.28524

Zhang, H., Kolb, F. A., Jaskiewicz, L., Westhof, E., and Filipowicz, W. (2004). Single processing center models for human Dicer and bacterial RNase III. Cell 118, 57-68. doi: 10.1016/j.cell.2004.06.017

Zhang, H., Nair, V., Saha, J., Atkins, K. B., Hodgin, J. B., Saunders, T. L., et al. (2017). Podocyte-specific JAK2 overexpression worsens diabetic kidney disease in mice. Kidney Int. 92, 909-921. doi: 10.1016/j.kint.2017.03.027

Zhang, S. Z., Qiu, X. J., Dong, S. S., Zhou, L. N., Zhu, Y., Wang, M. D., et al. (2019). MicroRNA-770-5p is involved in the development of diabetic nephropathy through regulating podocyte apoptosis by targeting TP53 regulated inhibitor of apoptosis 1. Eur. Rev. Med. Pharmacol. Sci. 23, 1248-1256. doi: 10.26355/ eurrev_201902_17018

Zhang, X., Song, S., and Luo, H. (2016). Regulation of podocyte lesions in diabetic nephropathy via miR-34a in the Notch signaling pathway. Medicine 95:e5050. doi: $10.1097 / \mathrm{md} .0000000000005050$

Zhao, B., Li, H., Liu, J., Han, P., Zhang, C., Bai, H., et al. (2016). MicroRNA$23 \mathrm{~b}$ targets ras GTPase-activating protein $\mathrm{SH} 3$ domain-binding protein 2 to alleviate fibrosis and albuminuria in diabetic nephropathy. J. Am. Soc. Nephrol. 27, 2597-2608. doi: 10.1681/asn.2015030300

Zhou, Z., Wan, J., Hou, X., Geng, J., Li, X., and Bai, X. (2017). MicroRNA-27a promotes podocyte injury via PPARgamma-mediated beta-catenin activation in diabetic nephropathy. Cell Death Dis. 8:e2658. doi: 10.1038/cddis.2017.74

Conflict of Interest: The authors declare that the research was conducted in the absence of any commercial or financial relationships that could be construed as a potential conflict of interest.

Copyright (C) 2020 Ishii, Kaneko, Yanai, Aomatsu, Hirai, Ookawara, Ishibashi and Morishita. This is an open-access article distributed under the terms of the Creative Commons Attribution License (CC BY). The use, distribution or reproduction in other forums is permitted, provided the original author(s) and the copyright owner(s) are credited and that the original publication in this journal is cited, in accordance with accepted academic practice. No use, distribution or reproduction is permitted which does not comply with these terms. 